\title{
Sex Differences in the Use of Complementary and Alternative Medicine among Adults with Multiple Chronic Conditions
}

\author{
Monira Alwhaibi $^{1,2}$ and Usha Sambamoorthi ${ }^{1}$ \\ ${ }^{1}$ Department of Pharmaceutical Systems and Policy, School of Pharmacy, West Virginia University, P.O. Box 9510, \\ Morgantown, WV 26506-9510, USA \\ ${ }^{2}$ Department of Clinical Pharmacy, School of Pharmacy, King Saud University, P.O. Box 2454, Riyadh 11451, Saudi Arabia
}

Correspondence should be addressed to Monira Alwhaibi; mmalwhaibi@mix.wvu.edu

Received 11 January 2016; Accepted 7 April 2016

Academic Editor: Waris Qidwai

Copyright (C) 2016 M. Alwhaibi and U. Sambamoorthi. This is an open access article distributed under the Creative Commons Attribution License, which permits unrestricted use, distribution, and reproduction in any medium, provided the original work is properly cited.

\begin{abstract}
Objective. To examine sex differences in complementary and alternative medicine (CAM) use among adults with multiple chronic conditions. Methods. This study used a cross-sectional design with data from the 2012 National Health Interview Survey. The participants were interviewed in 2012 and the reference period for the questions in the survey varied from 1 week to 12 months prior to the interview date. The study included adults (age $>21$ years) with no missing data on CAM use variables and who had multiple chronic conditions. Multivariable regression analyses were used to examine the association between sex and CAM use. Results. A significantly higher percentage of women compared to men had ever used CAM (51.5\% versus $44.3 \%$ ); women were more likely to have ever used CAM ( $\mathrm{AOR}=1.49,95 \% \mathrm{CI}=1.35-1.65)$. Among CAM users, a higher percentage of women compared to men used CAM in the past 12 months (53.5\% vs. $42.7 \%)$; women were more likely to use CAM in the past 12 months (AOR = 1.71 , $95 \% \mathrm{CI}=1.49-1.97)$. Factors associated with CAM use in the past 12 months were different for men and women; income and obesity were associated with CAM use in the past 12 months among women and not among men. Conclusion. Among adults with multiple chronic conditions, women were more likely to use CAM as compared to men.
\end{abstract}

\section{Introduction}

Complementary and alternative medicine (CAM) use is highly prevalent among adults. The worldwide prevalence of CAM use among adults can be as high as $75 \%$ [1]. In the United States (US), approximately $38 \%$ of adults use CAM [2]. Generally, adults use CAM to relieve negative symptoms of illnesses and to improve overall health [3]; CAM is also used because individuals experience side effects and do not get relief from conventional therapy [4]. CAM use is influenced by many factors including sex [5-7]. In adults with and without chronic conditions, sex differences in CAM use exist [5-10]. For example, among adults with diabetes women were more likely to use CAM than men $[9,10]$. Using data from the 2012 National Health Interview Survey (NHIS), one study reported that among adults with multiple chronic conditions (MCCs) a higher percentage of women used CAM as compared to men (52\% vs. $44 \%$ ) [5].
While the abovementioned studies documented higher rates of CAM use among women as compared to men, they did not examine whether there are sex differences in the association between demographic characteristics, socioeconomic characteristics, health status, and personal health practices and CAM use. Identifying the factors that influence the CAM use among men and women with MCCs is important because of the high and increasing prevalence of MCCs in the United States (US), specifically among women. It is estimated that one in four individuals has MCCs in all age groups, and the majority of those with MCCs are women [11]. Therefore, the objectives of the current study are to (1) examine sex differences in the use of CAM among adults with MCCs and (2) analyze sex differences in the associations between demographic characteristics, socioeconomic characteristics, health status, and personal health practices and CAM use among adults with MCCs. 


\section{Methods}

2.1. Study Design. This study was a retrospective crosssectional study using the National Health Interview Survey (NHIS) for the year 2012 among adults with multiple chronic conditions. Multiple chronic conditions were defined as having two or more chronic physical or mental health conditions.

2.2. Data Source. The current study used data from an annual survey of households in the US, the 2012 NHIS. The NHIS contains both core (household composition, family, sample child, and sample adults) and supplemental files. A randomly selected adult member ( $\geq 18$ years old) of a household was invited to complete the Adult CAM use questions, which resulted in the creation of adult CAM supplement file. The core files provide information on demographic characteristics, socioeconomic variables, chronic physical and mental health conditions, functional status, health status, and other variables. Chronic conditions were elicited by asking the participants whether they have ever been told by a doctor or other health professionals that they had a chronic condition. The list of chronic conditions included asthma, arthritis, cancer, chronic obstructive pulmonary disease (COPD), diabetes, heart diseases (angina pectoris, coronary heart disease, heart attack, stroke, and other heart conditions), hyperlipidemia, and hypertension, bipolar disorder, depression, or other mental health disorders. The CAM supplement file was used to obtain information on whether the respondent ever used CAM (see Tables 4 and 5) and, if so, whether they used CAM in the past 12 months. In this study, CAM use was identified using responses to questions related to 18 types of CAM.

2.3. Study Sample. The study sample comprised adults, aged $>21$ years, who responded to both adult core file and the CAM supplementary file. The study sample was further restricted to adults who reported having MCCs (i.e., two or more chronic physical conditions or having a combination of chronic physical and mental health conditions). MCCs were defined from the following list of chronic physical and mental health conditions: asthma, arthritis, cancer, chronic obstructive pulmonary disease (COPD), diabetes, heart diseases, hyperlipidemia, hypertension, bipolar disorder, depression, or other mental health disorders. In the study sample, we only included adults without any missing data on variables related to CAM use. The study sample consisted of 13,246 participants.

\subsection{Measures}

2.4.1. Dependent Variables: Ever Used CAM. Adults who have ever used any of the following types of CAM (acupuncture, ayurveda, homeopathy, naturopathy, alexander technique, chiropractic or osteopathic manipulation, craniosacral therapy, feldenkrais, massage, pilates, trager psychophysical integration, biofeedback, chelation therapy, energy healing therapy, hypnosis, qi gong, tai chi, and yoga) were defined as CAM users. Adults who used none of the 18 types of CAM were considered as nonusers of CAM.
CAM Use in the Past 12 Months among CAM Users. Adults who never used CAM were excluded and CAM use in the past 12 months was categorized into two groups among CAM users: (1) CAM users in the past 12 months; (2) nonusers of CAM in the past 12 months. Adults who reported using, at least, one of the 18 CAM types in the past 12 months were considered as "CAM users in the past 12 months." Adults who used none of the 18 types of CAM in the past 12 months were considered as "nonusers of CAM in the past 12 months."

2.4.2. Independent Variables. Variables used to examine the factors associated with CAM use in both men and women included demographic characteristics (age group in years, race/ethnicity, marital status, and the region of residence), socioeconomic characteristics (education, poverty status as measured by the federal poverty level (FPL), and health insurance coverage), health status (perceived health status, functional limitations, and the type of MCCs), and personal health practices (body mass index, smoking status, alcohol use, and physical activity (i.e., exercise)).

2.5. Statistical Analyses. Chi-square tests were used to describe sex differences in demographic characteristics, socioeconomic characteristics, health status, and personal health practices and to examine sex differences in CAM use. The adjusted relationships between sex and ever used CAM and CAM use in the last 12 months were examined with logistic regression models in which independent variables were entered in blocks. We included all the independent variables in the bivariate analyses in the multivariate analysis regardless of significance. Model I examined the unadjusted association between sex and CAM use (i.e., without controlling for any other independent variables). Model II controlled for demographic characteristics (age, race/ethnicity, and the region of residence). Model III controlled for socioeconomic characteristics (education level, marital status, health coverage, and poverty status). Model IV controlled for health status (perceived health, functional limitations, and MCCs) and Model V controlled for personal health practices (body mass index, smoking status, alcohol use, and physical activity).

In order to examine sex differences in the association between demographic characteristics, socioeconomic characteristics, health status, and personal health practices and ever used CAM and CAM use in the past 12 months, separate logistic regressions among women and men were conducted. All the analyses controlled for the complex survey design of NHIS and were conducted using survey procedure with Statistical Analysis System Software (SAS 9.4 Institute Inc., Cary, NC, USA).

\section{Results}

3.1. Description of the Study Sample by Sex. Table 1 displays the characteristics of the total study sample $(N=13,246)$ and the characteristics of the study sample by sex. There were statistically significant differences between men and women in demographic characteristics, socioeconomic characteristics, health status, and personal health practices. For example, as compared to men, a significantly higher percentage of women 
TABLE 1: Description of the study sample by sex. National Health Interview Survey 2012.

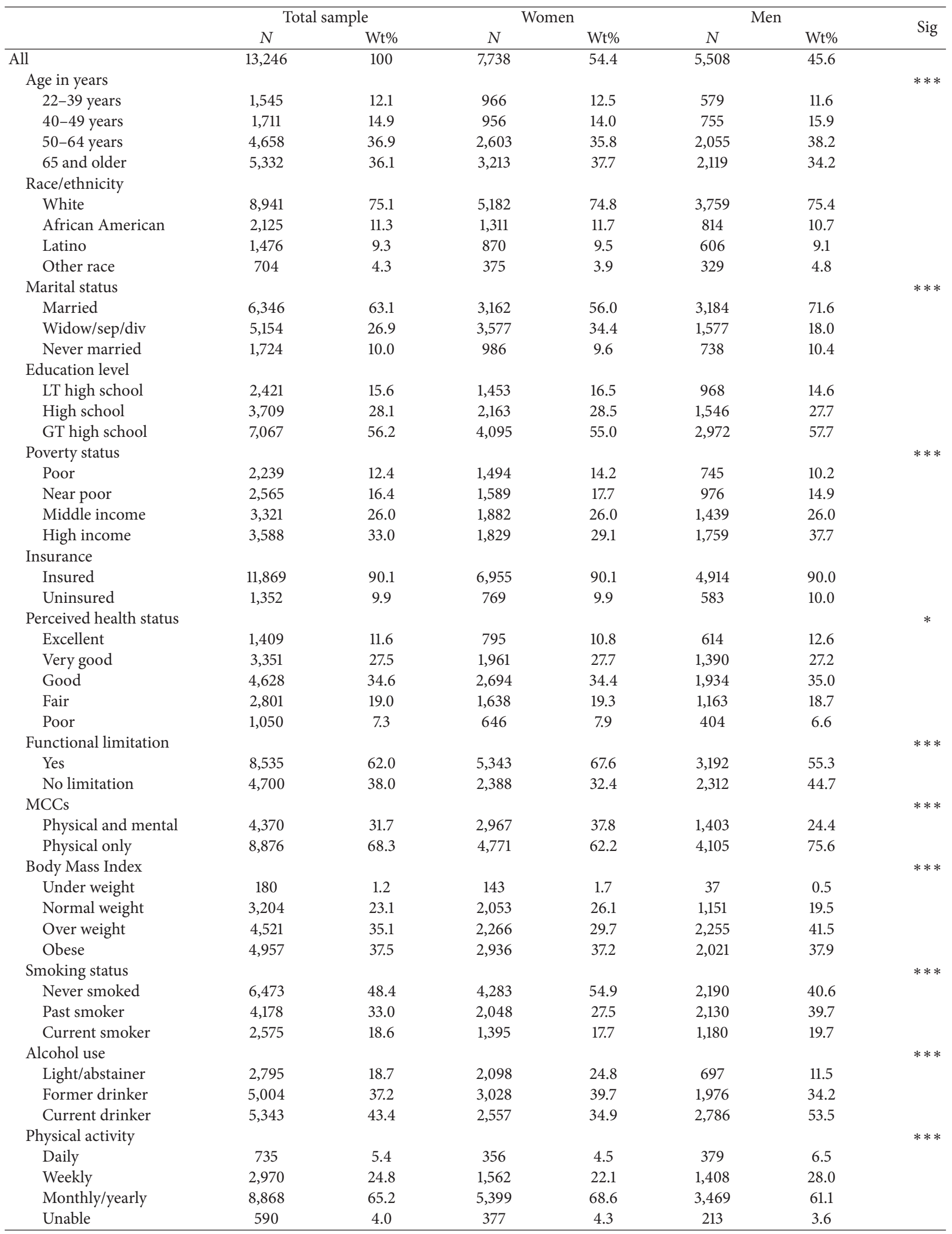


TABLE 1: Continued.

\begin{tabular}{|c|c|c|c|c|c|c|c|}
\hline & \multicolumn{2}{|c|}{ Total sample } & \multicolumn{2}{|c|}{ Women } & \multicolumn{2}{|c|}{ Men } & \multirow{2}{*}{ Sig } \\
\hline & $N$ & $\mathrm{Wt} \%$ & $N$ & $\mathrm{Wt} \%$ & $N$ & $\mathrm{Wt} \%$ & \\
\hline \multicolumn{8}{|l|}{ Region } \\
\hline Northeast & 2,193 & 17.2 & 1,308 & 17.5 & 885 & 16.8 & \\
\hline Midwest & 2,814 & 23.4 & 1,643 & 23.6 & 1,171 & 23.2 & \\
\hline South & 5,021 & 38.2 & 2,971 & 38.4 & 2,050 & 37.9 & \\
\hline West & 3,218 & 21.3 & 1,816 & 20.6 & 1,402 & 22.1 & \\
\hline
\end{tabular}

Note: based on 13,246 adults, age over 21 years, who had two or more chronic conditions (asthma, arthritis, cancer, chronic obstructive pulmonary disease, diabetes, heart diseases, hyperlipidemia, hypertension, bipolar disorder, depression, or other mental health disorders). Asterisks represent significant sex differences in baseline characteristics based on chi-square tests.

Missing indicators for alcohol use, exercise, body mass index, and poverty status were used but are not presented in the table. GT: greater than; LT: less than; Wt: weighted; MCCs: multiple chronic conditions; Wid/div/sep: widowed, divorced, and separated. ${ }^{* * *} p<.001 ;{ }^{*} .01 \leq p<.05$.

TABLE 2: Number and weighted percent of complementary and alternative medicine use by sex. National Health Interview Survey 2012.

\begin{tabular}{|c|c|c|c|c|c|c|c|}
\hline & \multicolumn{2}{|c|}{ Total sample } & \multicolumn{2}{|c|}{ Women } & \multicolumn{2}{|c|}{ Men } & \multirow{2}{*}{ Sig } \\
\hline & $N$ & $\mathrm{Wt} \%$ & $N$ & $\mathrm{Wt} \%$ & $N$ & $\mathrm{Wt} \%$ & \\
\hline Ever used CAM $(N=13,246)$ & & & & & & & $* * *$ \\
\hline Yes & 6,212 & 48.2 & 3,839 & 51.5 & 2,373 & 44.3 & \\
\hline No & 7,034 & 51.8 & 3,899 & 48.5 & 3,135 & 55.7 & \\
\hline All & 13,246 & 100 & 7,738 & 100 & 5,508 & 100 & \\
\hline CAM use, past 12 months $(N=6,212)$ & & & & & & & $* * *$ \\
\hline Yes & 3,037 & 49.0 & 2,015 & 53.5 & 1,022 & 42.7 & \\
\hline No & 3,175 & 51.0 & 1,824 & 46.5 & 1,351 & 57.3 & \\
\hline All & 6,212 & 100 & 3,839 & 100 & 2,373 & 100 & \\
\hline
\end{tabular}

Note: based on adults, age over 21 years, who had two or more chronic conditions (asthma, arthritis, cancer, chronic obstructive pulmonary disease, diabetes, heart diseases, hyperlipidemia, hypertension, bipolar disorder, depression, or other mental health disorders).

CAM use was based on 13,246 adults, and CAM use in the past 12 months was based on 6,212 CAM users.

Asterisks represent significant sex differences by Complementary Alternative Medicine use based on chi-square tests.

CAM: Complementary Alternative Medicine; Wt: weighted.

${ }^{* * *} p<.001$.

were poor (10.2\% versus $14.2 \%)$. Also, as compared to men, a significantly higher percentage of women had combined physical and mental MCCs (37.8\% versus $24.4 \%)$.

3.2. Sex Differences in Ever Used CAM. Table 2 summarizes unadjusted differences in CAM use by sex. There were statistically significant differences in CAM use between women and men. As compared to men, a significantly higher percentage of women had ever used CAM (44.3\% versus $51.9 \%)$. The logistic regressions on CAM use revealed that women were more likely than men to have ever used CAM. The Odds Ratios (OR) and 95\% confidence intervals (CI) for women after adjustment for demographic characteristics, socioeconomic status, health status, and personal health practices were as follows: $\mathrm{OR}=1.33,95 \% \mathrm{CI}=1.22,1.44 \mathrm{in}$ Model 1 and adjusted OR $(\mathrm{AOR})=1.49,95 \% \mathrm{CI}=1.35,1.65$ in Model 4 (Table 3).

3.3. Sex Differences in CAM Use in the Past 12 Months among CAM Users. Among CAM users, a statistically significant sex difference in CAM use in the past 12 months was observed. As compared to men, a significantly higher percentage of women used CAM in the past 12 months (42.7\% versus $53.5 \%$ ) (Table 2). The logistic regressions on CAM use in the past
12 months revealed that women were more likely than men to use CAM in the past 12 months. The Odds Ratios and 95\% confidence intervals for women after adjustment for demographic characteristics, socioeconomic status, health status, and personal health practices were as follows: $\mathrm{OR}=$ $1.56,95 \% \mathrm{CI}=1.36,1.78$ in Model 1 and $\mathrm{AOR}=1.62,95 \% \mathrm{CI}$ $=1.41,1.87$ in Model 4 (Table 3 ).

3.4. Sex Differences in Factors Affecting CAM Use. We found that factors associated with CAM use in the past 12 months were different for men and women. Women with low income were less likely to use CAM in the past 12 months as compared to women with high income $(\mathrm{AOR}=0.5,95 \% \mathrm{CI}=0.36$, $0.73)$; this was not the case with men. Men with functional limitations were more likely to use CAM in the past 12 months as compared to men with no functional limitations $(\mathrm{AOR}=$ $1.1,95 \%$ CI $=1.10,1.74)$. However, there was no significant relationship between functional status and CAM use in the past 12 months among women.

\section{Discussion}

This study used data from the 2012 NHIS to evaluate sex differences in CAM use among adults with MCCs and filled 
TABLE 3: Adjusted odds ratios and 95\% confidence intervals of women from pooled logistic regressions on ever used CAM and CAM use in the past 12 Months among CAM users. National Health Interview Survey 2012.

\begin{tabular}{|c|c|c|c|c|c|c|}
\hline & \multicolumn{3}{|c|}{ Ever used CAM $(N=13,246)$} & \multicolumn{3}{|c|}{ CAM use in past 12 months $(N=6,212)$} \\
\hline & AOR & $95 \% \mathrm{CI}$ & sig & $\mathrm{AOR}$ & $95 \% \mathrm{CI}$ & sig \\
\hline \multicolumn{7}{|c|}{ Model I, adjusted for only sex } \\
\hline Women & 1.33 & {$[1.22,1.44]$} & $* * *$ & 1.56 & {$[1.36,1.78]$} & $* * *$ \\
\hline \multicolumn{7}{|l|}{ Men (ref) } \\
\hline \multicolumn{7}{|c|}{ Model II, adjusted for demographic characteristics } \\
\hline Women & 1.43 & {$[1.31,1.55]$} & $* * *$ & 1.61 & {$[1.40,1.85]$} & $* * *$ \\
\hline \multicolumn{7}{|l|}{ Men (ref) } \\
\hline \multicolumn{7}{|c|}{ Model III, adjusted for demographic characteristics and socioeconomic characteristics } \\
\hline Women & 1.48 & {$[1.35,1.62]$} & $* * *$ & 1.63 & {$[1.42,1.87]$} & $* * *$ \\
\hline \multicolumn{7}{|l|}{ Men (ref) } \\
\hline \multicolumn{7}{|c|}{ Model IV, adjusted for demographic characteristics, socioeconomic characteristics, and health status } \\
\hline Women & 1.34 & {$[1.22,1.48]$} & $* * *$ & 1.56 & {$[1.36,1.79]$} & $* * *$ \\
\hline \multicolumn{7}{|l|}{ Men (ref) } \\
\hline \multicolumn{7}{|c|}{ Model V, adjusted for demographic characteristics, socioeconomic characteristics, health status, and personal health practices } \\
\hline Women & 1.49 & {$[1.35,1.65]$} & $* * *$ & 1.62 & {$[1.41,1.87]$} & $* * *$ \\
\hline \multicolumn{7}{|l|}{ Men (ref) } \\
\hline \multicolumn{7}{|c|}{$\begin{array}{l}\text { Note: logistic regression on CAM use was based on } 13,246 \text { adults, age over } 21 \text { years, who had two or more chronic condi } \\
\text { obstructive pulmonary disease, diabetes, heart diseases, hyperlipidemia, hypertension, bipolar disorder, depression, or } \\
\text { regression on CAM use in past } 12 \text { months was based on 6,212 CAM users. Asterisks represent significant sex difference } \\
\text { use and CAM use in the past } 12 \text { months. } \\
\text { AOR: adjusted odds ratios; CAM: Complementary Alternative Medicine; CI: confidence interval; ref: reference group. } \\
{ }^{* * *} p<.001 \text {. }\end{array}$} \\
\hline
\end{tabular}

knowledge gap about the sex differences in factors affecting CAM use. Past studies in the literature have investigated sex differences in CAM use among adults with and without a specific condition (e.g., diabetes versus no diabetes) [5$8,10]$. To date, the current study is the first one to examine sex differences in CAM use among adults with MCCs. In the current study, even after adjustment for many factors, sex differences in CAM use persisted. Other studies have attributed the higher rates of CAM use among women as compared to men to the sex differences in propensity to seek care $[12,13]$. Future research needs to explore factors such as attitude, preferences, and failure of conventional therapies to relieve suffering from chronic illnesses to explain sex differences in CAM use.

Although many studies have documented that women were more likely to use CAM than men $[5-8,10]$, our study extended the prior literature by also evaluating the factors associated with CAM use in women and men separately. We found sex differences in factors that affect CAM therapy in the past 12 months. For example, women with lower income levels were less likely to use CAM in the past 12 months as compared to those with high income. This was not the case among men. We also found that $33 \%$ of women and $37 \%$ of men had high income as measured by FPL. These findings suggest that low income may be greater barrier to CAM use among women than among men. Future research needs to explore whether policies that reduce economic disparities between men and women can eliminate the sex disparities in CAM use due to income.
Women with obesity were less likely to use CAM in the past 12 months as compared to women with normal BMI; this was not the case with men. Although prior studies have documented lower rates of CAM use among adults with obesity [14], they did not analyze the interaction between sex and obesity. While we do not know the reasons for this finding, there is some evidence that women with obesity may avoid healthcare services [15]. Future research needs to explore the barriers to CAM use among women with obesity.

Women with both physical and mental health conditions were more likely to use CAM in the past 12 months as compared to those women with only chronic physical conditions; no such relationship was found among men. We also found that a higher percentage of women $(37.8 \%)$ than men $(24.4 \%)$ suffered from both chronic physical and mental health conditions. In prior studies, it has been found that a higher percentage of women than men used CAM therapies for mental health conditions [16]. Given that many women suffer from depression and depression was included in our list of MCCs, the higher prevalence of CAM use among women may also be driven by the presence of depression among women. Previous studies have found that women with depression use therapies such as chiropractic, massage, and acupressure to relieve depressive symptoms [4]. Therefore, it is plausible that the type of MCCs was related to CAM use among women and not among men. We observed that men with functional limitations were more likely to use CAM as compared to those without functional limitations; this relationship was not found among women. This was unexpected 
TABLE 4: Adjusted odds ratios and 95\% confidence intervals of significant independent variables from separate logistic regressions of women and men on ever used CAM. National Health Interview Survey 2012.

\begin{tabular}{|c|c|c|c|c|c|c|}
\hline \multirow{2}{*}{. } & \multicolumn{3}{|c|}{ Women } & \multicolumn{3}{|c|}{ Men } \\
\hline & AOR & $95 \% \mathrm{CI}$ & Sig & AOR & $95 \% \mathrm{CI}$ & Sig \\
\hline \multicolumn{7}{|l|}{ Race/ethnicity } \\
\hline \multicolumn{7}{|l|}{ White (ref) } \\
\hline African American & 0.57 & {$[0.47,0.69]$} & $* * *$ & 0.54 & {$[0.43,0.68]$} & $* * *$ \\
\hline Latino & 0.68 & {$[0.55,0.84]$} & $* * *$ & 0.68 & {$[0.51,0.89]$} & $* *$ \\
\hline Other & 0.96 & {$[0.70,1.31]$} & & 0.74 & {$[0.52,1.04]$} & \\
\hline \multicolumn{7}{|l|}{ Marital status } \\
\hline Married & 0.97 & {$[0.79,1.18]$} & & 1.50 & {$[1.18,1.91]$} & $* * *$ \\
\hline Widow/sep/div & 0.97 & {$[0.81,1.17]$} & & 1.33 & {$[1.02,1.73]$} & * \\
\hline \multicolumn{7}{|l|}{ Never married (ref.) } \\
\hline \multicolumn{7}{|l|}{ Education level } \\
\hline LT high school & 0.46 & {$[0.38,0.56]$} & $* * *$ & 0.52 & {$[0.41,0.65]$} & $* * *$ \\
\hline High school & 0.58 & {$[0.50,0.68]$} & $* * *$ & 0.84 & {$[0.72,0.99]$} & * \\
\hline \multicolumn{7}{|l|}{ GT high school (ref) } \\
\hline \multicolumn{7}{|l|}{ Poverty status (FPL) } \\
\hline Poor & 0.44 & {$[0.34,0.56]$} & $* * *$ & 0.68 & {$[0.48,0.96]$} & * \\
\hline Near poor & 0.74 & {$[0.60,0.91]$} & $* *$ & 0.65 & {$[0.51,0.84]$} & $* * *$ \\
\hline Middle income & 0.70 & {$[0.58,0.85]$} & $* * *$ & 0.90 & {$[0.75,1.08]$} & \\
\hline \multicolumn{7}{|l|}{ High Income (ref) } \\
\hline \multicolumn{7}{|l|}{ MCCs } \\
\hline \multicolumn{7}{|l|}{ Physical only (ref) } \\
\hline Physical and mental & 1.78 & {$[1.54,2.06]$} & $* * *$ & 1.57 & {$[1.29,1.91]$} & $* * *$ \\
\hline \multicolumn{7}{|l|}{ Functional limitation } \\
\hline Limitation & 1.61 & {$[1.37,1.90]$} & $* * *$ & 1.69 & {$[1.42,2.01]$} & $* * *$ \\
\hline \multicolumn{7}{|l|}{ No limitation (ref) } \\
\hline \multicolumn{7}{|l|}{ Smoking status } \\
\hline \multicolumn{7}{|l|}{ Never smoked (ref) } \\
\hline Past smoker & 1.11 & {$[0.95,1.31]$} & & 1.18 & {$[1.00,1.41]$} & \\
\hline Current smoker & 0.78 & {$[0.66,0.93]$} & $* *$ & 1.01 & {$[0.81,1.26]$} & \\
\hline \multicolumn{7}{|l|}{ Alcohol use } \\
\hline \multicolumn{7}{|c|}{ Lifetime abstainer (ref) } \\
\hline Former drinker & 1.40 & {$[1.18,1.65]$} & $* * *$ & 1.49 & {$[1.18,1.87]$} & $* * *$ \\
\hline Current drinker & 1.80 & {$[1.49,2.17]$} & $* * *$ & 1.49 & {$[1.18,1.89]$} & $* * *$ \\
\hline \multicolumn{7}{|l|}{ Physical activity } \\
\hline \multicolumn{7}{|l|}{ Weekly (ref) } \\
\hline Daily & 1.02 & {$[0.71,1.46]$} & & 1.07 & {$[0.80,1.45]$} & \\
\hline Monthly/yearly & 0.56 & {$[0.47,0.68]$} & $* * *$ & 0.79 & {$[0.67,0.92]$} & $* *$ \\
\hline Unable & 0.41 & {$[0.28,0.62]$} & $* * *$ & 0.54 & {$[0.36,0.83]$} & $* *$ \\
\hline \multicolumn{7}{|l|}{ Region } \\
\hline Northeast & 0.56 & {$[0.45,0.69]$} & $* * *$ & 0.67 & {$[0.52,0.86]$} & $* *$ \\
\hline Midwest & 0.87 & {$[0.71,1.07]$} & & 0.73 & {$[0.58,0.92]$} & $* *$ \\
\hline South & 0.53 & {$[0.44,0.64]$} & $* * *$ & 0.58 & {$[0.48,0.71]$} & $* * *$ \\
\hline West (ref) & & & & & & \\
\hline
\end{tabular}

Note: based on 13,246 adults, age over 21 years, who had two or more chronic conditions (asthma, arthritis, cancer, chronic obstructive pulmonary disease, diabetes, heart diseases, hyperlipidemia, hypertension, bipolar disorder, depression, and other mental health disorders). Asterisks represent significant group differences compared to the reference group based on binary logistic regressions on ever used CAM.

AORs for the following variables are not presented because they were not statistically significant: age, health insurance coverage, and perceived health status. Missing indicators for alcohol use, exercise, body mass index, and poverty status were used but are not presented in the table.

AOR: adjusted odds ratios; CI: confidence interval; LT: less than; GT: greater than; MCCs: multiple chronic conditions; Wid/div/sep: widowed, divorced, and separated; Wt: weighted.

${ }^{* * *} p<.001 ;{ }^{* *} .001 \leq p<.01 ;{ }^{*} .01 \leq p<.05$. 
TABLE 5: Adjusted odds ratios and 95\% confidence intervals of significant independent variables from logistic regression on complementary and alternative medicine use in the past 12 months among adults with complementary and alternative medicine use. National Health Interview Survey 2012.

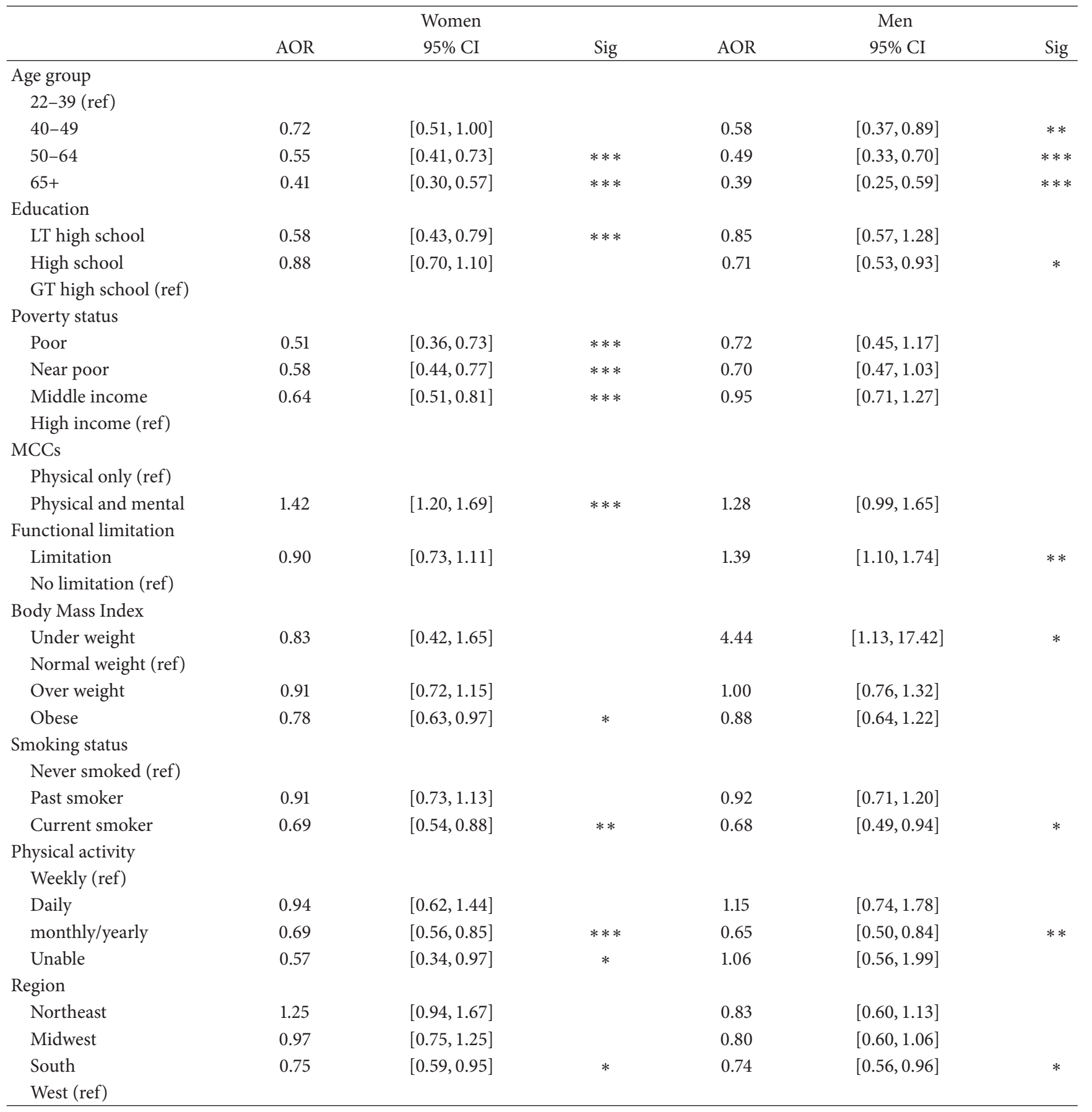

Note: based on 6,212 CAM users, age over 21 years, who had two or more chronic conditions (asthma, arthritis, cancer, chronic obstructive pulmonary disease, diabetes, heart diseases, hyperlipidemia, hypertension, bipolar disorder, depression, and other mental health disorders). Asterisks represent significant group differences compared to the reference group based on binary logistic regressions on ever used CAM.

AORs for the following variables are not presented because they were not statistically significant: race/ethnicity, health insurance coverage, and perceived health status.

Missing indicators for alcohol use, exercise, body mass index, and poverty status were used but are not presented in the table.

AOR: adjusted odds ratios; CI: confidence interval; LT: less than; GT: greater than; MCCs: multiple chronic conditions; Wid/div/sep: widowed, divorced, and separated; Wt: weighted.

${ }^{* * *} p<.001 ;{ }^{* *} .001 \leq p<.01 ;{ }^{*} .01 \leq p<.05$. 
as prior research among documented women with functional limitations had a higher use of CAM as compared to those without functional limitations [17]. However, these studies were not specific to individuals with MCCs. It is plausible that among women and men with MCCs functional limitation may not be a barrier to CAM use. Future research needs to explore this issue further.

This study has many advantages. It used a nationally representative data with large sample size and included adults with MCCs. It also evaluated the association between sex and CAM use after controlling for a comprehensive list of factors that affect CAM use. However, results of this study should be interpreted in the context of some limitations. All measures in the study were self-reported and thus subject to recall bias. This study did not control for other factors that affect the use of CAM such as severity of chronic conditions, pain, fatigue, beliefs, and attitudes towards CAM use.

\section{Conclusion}

The current study sought to understand the sex differences in the use of CAM among adults with MCCs. We found that women were more likely to use CAM as compared to men and factors affecting CAM use in the past 12 months were different for women and men. As the clinical efficacy and effectiveness of many of the CAM therapies for treating chronic conditions have not been established, healthcare providers treating women for chronic conditions need to be aware of the high prevalence of CAM use among women with MCCs.

\section{Competing Interests}

The authors declare that they have no competing interests.

\section{Acknowledgments}

Dr. Usha Sambamoorthi received support from the National Institute of Health/National Institute of General Medical Sciences (NIH/NIGMS) Award Grant no. U54GM104942.

\section{References}

[1] M. Frass, R. P. Strassl, H. Friehs, M. Müllner, M. Kundi, and A. D. Kaye, "Use and acceptance of complementary and alternative medicine among the general population and medical personnel: a systematic review," The Ochsner Journal, vol. 12, no. 1, pp. 4556, 2012.

[2] National Center for Complementary and Integrative Health, The Use of Complementary and Alternative Medicine in the United States, National Center for Complementary and Integrative Health, 2008, https://nccih.nih.gov/research/statistics/2007/camsurvey_fs1.htm.

[3] J. Shen, R. Andersen, P. S. Albert et al., "Use of complementary/alternative therapies by women with advanced-stage breast cancer," BMC Complementary and Alternative Medicine, vol. 2, article 8, 2002.

[4] P. Wu, C. Fuller, X. Liu et al., "Use of complementary and alternative medicine among women with depression: results of a national survey," Psychiatric Services, vol. 58, no. 3, pp. 349-356, 2007.

[5] M. Alwhaibi, R. Bhattacharya, and U. Sambamoorthi, "Type of multimorbidity and complementary and alternative medicine use among adults," Evidence-Based Complementary and Alternative Medicine, vol. 2015, Article ID 362582, 9 pages, 2015.

[6] P. M. Barnes, B. Bloom, and R. L. Nahin, "Complementary and alternative medicine use among adults and children: United States, 2007," National Health Statistics Reports, no. 12, pp. 1-23, 2009.

[7] M. A. Laiyemo, G. Nunlee-Bland, F. A. Lombardo, R. G. Adams, and A. O. Laiyemo, "Characteristics and health perceptions of complementary and alternative medicine users in the United States," American Journal of the Medical Sciences, vol. 349, no. 2, pp. 140-144, 2015.

[8] F. L. Bishop, L. Yardley, and G. Lewith, "Developing a measure of treatment beliefs: the complementary and alternative medicine beliefs inventory," Complementary Therapies in Medicine, vol. 13, no. 2, pp. 144-149, 2005.

[9] R. A. Bell, C. K. Suerken, J. G. Grzywacz, W. Lang, S. A. Quandt, and T. A. Arcury, "Complementary and alternative medicine use among adults with diabetes in the United States," Alternative Therapies in Health and Medicine, vol. 12, no. 5, pp. 16-22, 2006.

[10] L. E. Egede, X. Ye, D. Zheng, and M. D. Silverstein, “The prevalence and pattern of complementary and alternative medicine use in individuals with diabetes," Diabetes Care, vol. 25, no. 2, pp. 324-329, 2002.

[11] Robert Wood Johnson Foundation, Chronic Conditions: Making the Case for Ongoing Care, 2004, http://www.partnershipforsolutions.org/DMS/files/chronicbook2004.pdf.

[12] K. D. Bertakis, R. Azari, L. J. Helms, E. J. Callahan, and J. A. Robbins, "Gender differences in the utilization of health care services," Journal of Family Practice, vol. 49, no. 2, pp. 147-152, 2000.

[13] V. Vaidya, G. Partha, and M. Karmakar, "Gender differences in utilization of preventive care services in the United States," Journal of Women's Health, vol. 21, no. 2, pp. 140-145, 2012.

[14] S. M. Bertisch, C. C. Wee, and E. P. McCarthy, "Use of complementary and alternative therapies by overweight and obese adults," Obesity, vol. 16, no. 7, pp. 1610-1615, 2008.

[15] C. A. A. Drury and M. Louis, "Exploring the association between body weight, stigma of obesity, and health care avoidance," Journal of the American Academy of Nurse Practitioners, vol. 14, no. 12, pp. 554-561, 2002.

[16] A. T. Woodward, K. M. Bullard, R. J. Taylor et al., "Complementary and alternative medicine for mental disorders among African Americans, Black Caribbeans, and Whites," Psychiatric Services, vol. 60, no. 10, pp. 1342-1349, 2009.

[17] C. A. Okoro, G. Zhao, C. Li, and L. S. Balluz, "Use of complementary and alternative medicine among US adults with and without functional limitations," Disability and Rehabilitation, vol. 34, no. 2, pp. 128-135, 2012. 


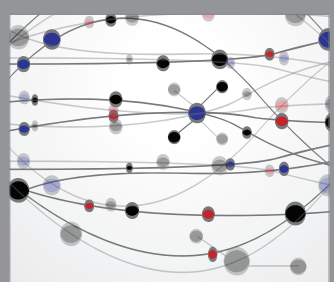

The Scientific World Journal
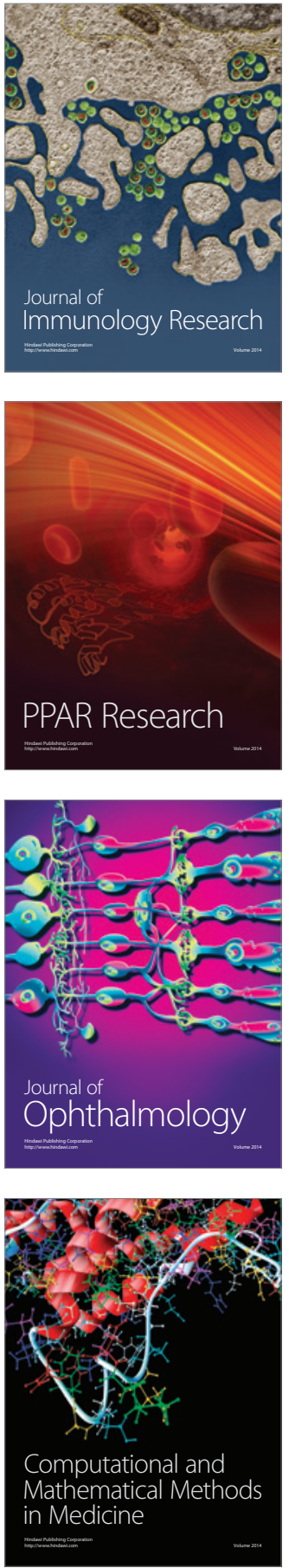

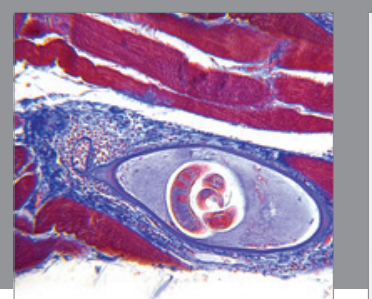

Gastroenterology Research and Practice

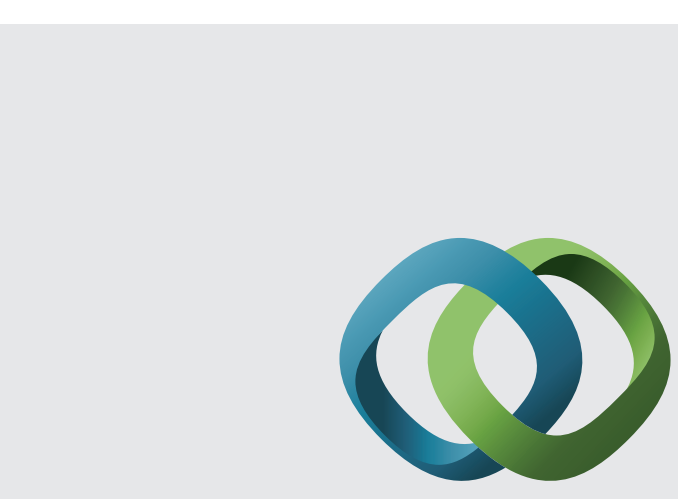

\section{Hindawi}

Submit your manuscripts at

http://www.hindawi.com
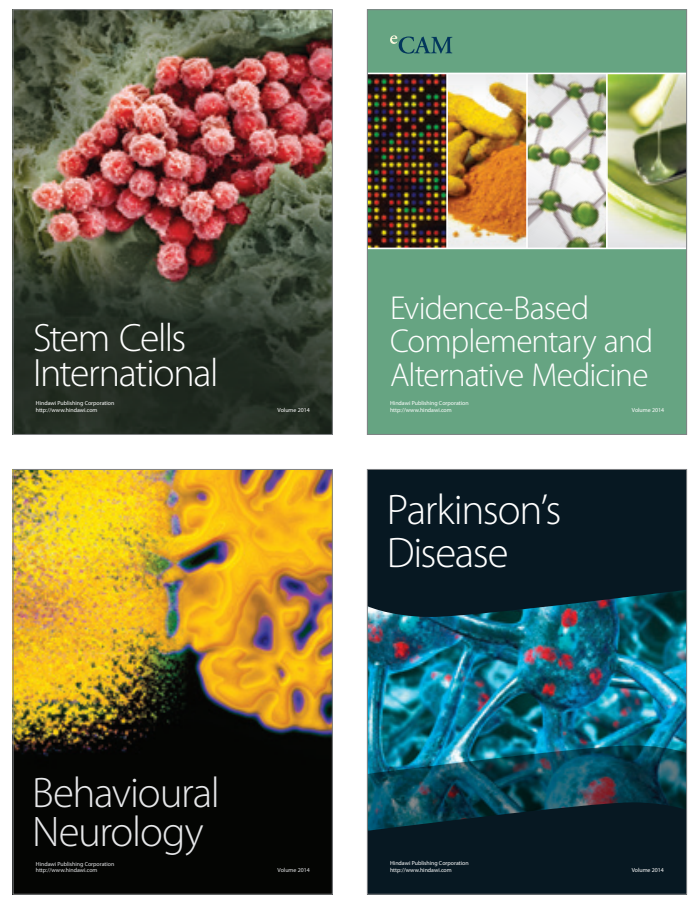
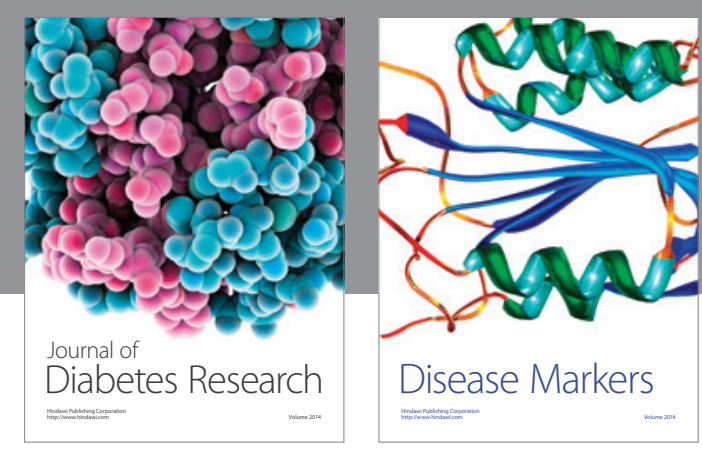

Disease Markers
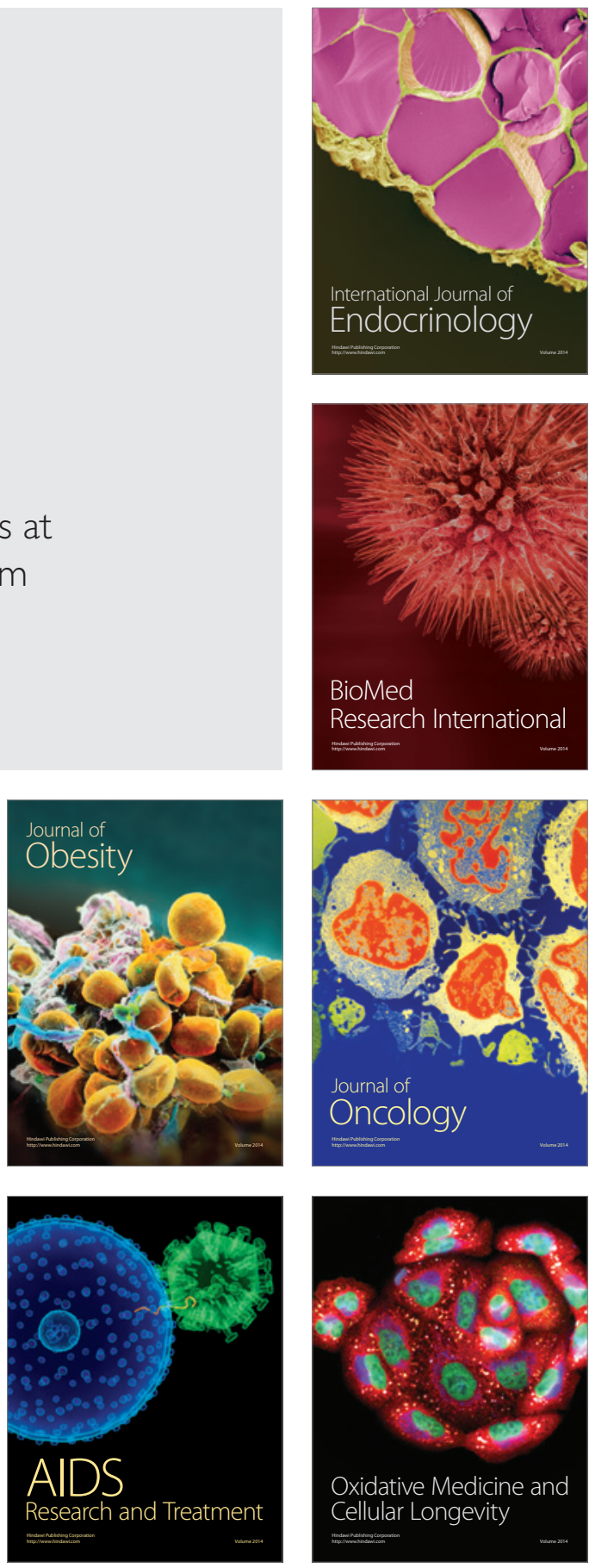